\begin{tabular}{|c|c|c|}
\hline 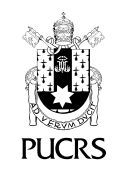 & $\begin{array}{l}\text { ESCOLA DE } \\
\text { HUMANIDADES }\end{array}$ & $\begin{array}{l}\text { Revista Digital do Programa de Pós-Graduação em Letras da PUCRS } \\
\text { Letrônica, Porto Alegre, v. 13, n. 2, p. 1-17, abr.-jun. } 2020 \\
\text { e-ISSN: 1984-4301 }\end{array}$ \\
\hline ttp:// & $34-4301.2020 .2 .37411$ & \\
\hline
\end{tabular}

\title{
Tonos intolerantes en discursos de grandes medios de comunicación brasileños: un estudio dialógico
}

\author{
Tons intolerantes em discursos da grande midia brasileira: uma abordagem dialógica \\ Intolerant tones in the discourse of brazilian mass media: a dialogical approach
}

\section{Maria da Glória Corrêa di Fanti ${ }^{1}$ orcid.org/0000-0002-5399-5377 gloria.difanti@pucrs.br}

\section{Juan Manuel López- \\ Muñoz ${ }^{2}$ \\ orcid.org/0000-0002-2208-2540 jmanuel.lopez@uca.es}

Recebido em: 20 jan. 2020 Aprovado em: 23 mar. 2020. Publicado em: 13 ago. 2020.

\begin{abstract}
RESUMEN: Este artículo tiene como objetivo presentar un estudio dialógico de discursos con tonos intolerantes contra la presidenta Dilma Rousseff propagados por los grandes medios de comunicación brasileños en el momento del proceso de destitución. En concreto, se analizan enunciados verbo-visuales de la revista Isto É, del 06/04/2016, y del periódico Folha de S. Paulo, del 02/05/2016, observando las características de producción de tales discursos y la forma en que la destinataria se ve afectada por la intolerancia. Los resultados revelan que los tonos intolerantes, al mismo tiempo que se dirigen a una determinada víctima, presuponen un coro de apoyo que comparte unas mismas valoraciones y participa en la producción, recepción y circulación, fomentando la intolerancia y la polarización de la sociedad. Las reflexiones desarrolladas en el presente artículo destacan la importancia de la responsabilidad de los medios de comunicación de masas en el fomento del respeto por las diferencias, el compromiso activo crítico con los problemas sociales y el impulso del diálogo con el fin reorientar su coro de apoyo a la preservación de los valores democráticos, indispensables para enfrentar la crisis actual de intolerancia.
\end{abstract}

PALABRAS CLAVE: discurso intolerante; tono/entonación expresiva; enunciado verbo-visual; confrontación de voces; medios de comunicación

RESUMO: O presente artigo tem como objetivo apresentar uma análise dialógica de discursos com tons intolerantes contra a presidenta Dilma Rousseff propagados pela grande mídia à época do processo de impeachment. Para tanto, com base na perspectiva dialógica do discurso, são analisados enunciados verbo-visuais da revista Isto É, de 06/04/2016, e do jornal Folha de S. Paulo, de 02/05/2016, observando caracteristicas da produção de tais discursos e do modo como o sujeito é atingido pela intolerância. Os resultados revelam que os tons intolerantes ao mesmo tempo que são endereçados a uma determinada vitima, pressupõem um coro de apoio, que compartilha valorações comuns e alimenta a sua produção, recepção e circulação, fomentando a intolerância e a polarização da sociedade. As reflexões desenvolvidas no presente artigo convocam a pensar sobre o importante papel de uma mídia responsável, que respeite as diferenças, sendo atuante, crítica, investigativa e comprometida com as questões sociais, de modo a reivindicar um coro de apoio voltado não só para o enfrentamento da atual crise de intolerância, mas também para a preservação dos valores democráticos.

PALAVRAS-CHAVE: discurso intolerante; tom/entonação expressiva; enunciado verbo-visual; confronto de vozes; mídia.

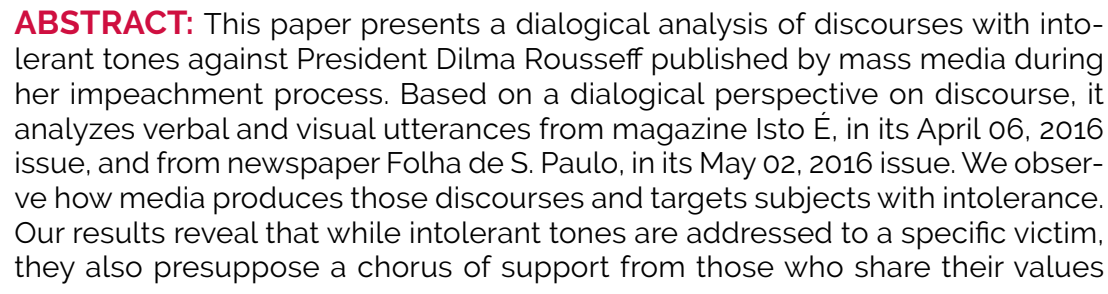

Artigo está licenciado sob forma de uma licença Creative Commons Atribuição 4.0 Internacional. 
and feed their production, reception, and transmission. This process encourages intolerance and polarization within society. The arguments made in this paper lead us to think about the relevant role played by a responsible media that respects differences and is proactive, critical, investigative, and committed to social issues. This results in a chorus of support focused not only on fighting against the current intolerance crisis but also on preserving democratic values.

KEYWORDS: intolerant discourses; tone/expressive intonation; verbal and visual utterances; heteroglossia; media.

\section{Preliminares}

Hemos escrito recientemente sobre los problemas epistemológicos y metodológicos que plantea el estudio de los discursos intimidatorios, entre los que incluiamos entonces las amenazas verbales, el ciberacoso y los discursos de odio (LÓPEZ-MUÑOZ \& CAPPPONI, 2017) y sobre la alteridad constitutiva de la producción de significados en situaciones de confrontación de identidades (DI FANTI et al., 2018). Volvemos ahora sobre este tema desde un enfoque diferente, en relación con la cuestión de la (in)tolerancia, con la intención de aportar algunas observaciones nuevas, además de las ya presentadas en el texto Discursos (int)tolerantes y democracia pluralista (LÓPEZ-MUÑOZ \& DI FANTI, 2020), que abre este número sobre Discurso intolerante na contemporaneidade.

Sabemos que la tolerancia no solo concierne a las religiones sino, en general, nuestra actitud hacia las formas de pensar, decir y hacer de los demás. Así, la tolerancia requiere respeto a las diferencias y se construye en el día a día de interacciones sociales, en las que cada persona se encuentra con otras que no necesariamente viven y piensan de la misma manera (DROIT, 2016). Bajo esta perspectiva, según Droit (2017, p. 70), no todo es tolerable. Además de los actos habitualmente considerados intolerables, como el asesinato y el robo, siguiendo al filósofo, se encuentran la falta de respeto por la integridad física de una persona, la violencia, el desprecio, la deslealtad, la traición y la injusticia. En las decisiones diarias, en casos específicos, las fronteras a menudo son difusas entre lo que es tolerable y lo que no; son relativamente variables y, sobre todo, discutibles. Por esta razón, continúa afirmando Droit, es necesario debatir, reflexionar colectivamente, examinar los puntos de vista para buscar formas que eviten que los actos intolerables se propaguen (Ibid, p. 74). Entre tales formas, ser intolerante con lo intolerable es una medida necesaria en tanto que, por un lado, hace retroceder la intolerancia y, por otro, contribuye al aumento de la tolerancia y al fortalecimiento de la democracia.

Nuestras reflexiones apuntan a la idea de que el problema de la intolerancia no solo atañe a un determinado locutor (un pretendido individuo intolerante o "hater") sino a la sociedad entera, es decir, a cualquier participante en un acto de conversación, y que atañe muy particularmente al sujeto anatematizado (o "sufferer"). Por decirlo resumidamente, creemos que los estudios sobre los discursos intolerantes, injuriosos, discriminatorios o de odio, parecen haberse centrado la mayoria de las veces ${ }^{3}$ en el análisis (principalmente descriptivo, cualitativo y cuantitativo) de la producción de los locutores intolerantes y la difusión de los discursos de estos desde una perspectiva juridico-lingüistica, lo que sin duda ha servido para mejorar la identificación de tales locutores (tratados como potenciales delincuentes) y de los discursos intolerantes (tratados como potenciales delitos).

Es la toma de consciencia de esto lo que nos mueve ahora a plantear un nuevo enfoque para la investigación, desde una perspectiva dialógica que, observando el discurso mediático, procura ver cómo los sujetos anatematizados, la(s) victima(s) ${ }^{4}$, se ven afectados en el entretejido y la estructura de los discursos, lo que nos mueve a indagar además en las causas y los efectos (no siempre distinguibles entre si) de los discursos intolerantes tanto en el ciberespacio como en el mundo offline. En tal contexto, nos interesamos por las manifestaciones intolerantes transmitidas por algunos de los grandes medios de comunicación

\footnotetext{
3 Véanse Alcácer Guirao (2013), Bertoni (2007), Espinoza Ariza (2015), Esquivel Alonso (2016) Ferreiro Galguera (2006), Revenga Sánchez (2004, 2008 y 2015); además de Rodriguez Montañés (2012), entre otros.

4 Véase Alcácer Guirao (2015, p. 45-86).
} 
brasileños, a menudo disfrazadas de información y / u opinión, interfiriendo directa o indirectamente en la construcción de la opinión pública. Esto se ve especialmente agravado en los momentos decisivos de elecciones presidenciales y durante los Llamados juicios políticos. Desde esta perspectiva, nuestro objetivo es presentar un estudio acompañado de numerosas reflexiones sobre el discurso con tonos intolerantes contra la presidenta Dilma Rousseff, predominantemente propagado en las portadas de la revista Isto É y el periódico Folha de S. Paulo en el momento del proceso de impeachment de 2016, prestando atención a cómo se generan y se constituyen los tonos intolerantes en tales enunciados mediáticos al objeto de conseguir agraviar al sujeto afectado. Esta selección, además de permitirnos contemplar diferentes materializaciones discursivas de la intolerancia, en dos vehículos de comunicación diferentes igualmente importantes en el contexto brasileño, está justificada por el hecho de que ambos, tanto en sus formatos impresos como en línea, son la fuente principal de información para gran parte de la población, hasta el punto de que sus portadas circulan en diferentes espacios y se comparten ampliamente en Internet y las redes sociales.

Dicho esto, hemos organizado este artículo en tres partes, seguidas de las consideraciones finales. En el primero, discutimos quiénes serian las víctimas de los discursos intolerantes, en general y en el actual contexto brasileño en particular, teniendo en cuenta la histórica negación de la intolerancia en este país, por un lado, y su exacerbación en los tiempos contemporáneos, por el otro. En la segunda parte, discutimos algunas de las principales teorias que contribuyen al análisis del discurso intolerante. Finalmente, en la tercera parte, presentamos algunas reflexiones metodológicas y procedemos al análisis del corpus seleccionado.

\section{¿Quiénes son las víctimas de la intolerancia?}

El discurso oficial ${ }^{5}$ respecto a la naturaleza de las potenciales victimas de los discursos de odio e intolerancia no es unánime. La lista, variable según los países, destaca un conjunto desordenado de criterios empleables: raza, etnia, nacionalidad, religión, género, orientación sexual, edad, discapacidad o enfermedad, sin especificar en ningún caso qué colectivos concretos son generalmente el blanco del odio. Las principales plataformas de interacción digital tratan este tema con la misma falta de precisión y de unanimidad. Por ejemplo, Twitter ${ }^{6}$, señala como contenido prohibido el uso de un "lenguaje de incitación al odio o de enfrentamiento en contra de un grupo, una persona o una organización protegidos (sic) por razones de: raza, origen étnico, color, nacionalidad, orientación sexual, sexo, identidad de género, afiliación religiosa, edad, discapacidad, afección médica o genética, condición de veterano de guerra, condición de refugiado, condición de inmigrante", en ese orden. Facebook, por su parte, prohíbe el uso del "lenguaje ofensivo, amenazas creíbles o ataques directos a un individuo o un grupo nacional, racial, religioso o étnico"7, asi como "cualquier cosa que ataque directamente a las personas en base a lo que se conoce como sus caracteristicas protegidas (sic): raza, origen étnico, origen nacional, afiliación religiosa, orientación sexual, sexo, género, identidad de género o discapacidad o enfermedad grave".

Se habla, como vemos, de ciertas "características protegidas" o "grupos protegidos", pero no se especifica qué grupos o personas exactamente (¿de qué raza?, ¿de qué sexo?, ¿de qué edad?, ¿de qué nacionalidad?, ¿con qué enfermedad? ...) suelen ser el objeto de los comportamientos discursivos intolerantes. Este no-dicho nos parece muy revelador, y justifica precisamente que en adelante los estudios se

\footnotetext{
5 Hemos destacado, en el texto introductor del presente número de Letrônica, los principales manuales de referencia, publicados por la Asamblea Parlamentaria del Consejo de Europa, la Organización de los Estados Americanos, el Parlamento Europeo, la Comisión Europea contra el Racismo y la Intolerancia, la Asamblea General de las Naciones Unidas y La Organización de las Naciones Unidas para la Educación, la Ciencia y la Cultura.

6 La información está disponible en la página oficial de Twitter, en la sección de políticas relativas a contenidos prohibidos: https:// business.twitter.com/es/help/ads-policies/prohibited-content-policies/hate-content.html

7 https://www.gesetze-im-internet.de/stgb/___130.html
} 
deban esforzar en colmar tal laguna.

La propia calificación de "víctima" plantea ya por si misma problemas de difícil solución, al no ser un término neutral. Charaudeau (2019, s/p) señala que los llamados "estados de víctima", y "discursos de victimización" están marcados por una relación de subjetividad, de la víctima respecto a la agresión misma, por un lado, y al sufrimiento por el proceso, por otro lado. En una combinación de afecto y razón.

Y, luego, está el problema, quizá más preocupante, de ¿cómo poder ofrecer recursos a las potenciales víctimas para contrarrestar su propia vulnerabilidad? (LAVERGNE, 2019), teniendo en cuenta que, siguiendo a Guillaume Surin (2019), la vulnerabilidad es una disposición de cualquier individuo; es decir, es parte constitutiva de la humanidad en general, como una condición de las personas definidas en su relación con la escritura, y su habilidad para producir y ser objeto de discursos, en el desarrollo de las interacciones sociales. En este sentido, la víctima solo parece tener razón de ser en un mundo donde se acepta un cierto grado inevitable de violencia; cabe preguntarse entonces, con Chantal Maillard, si sería posible un mundo sin violencia, en cuyo caso hipotético la tolerancia se asemejaría, salvando las diferencias, a la no-violencia (MAILLARD, 2018, p. 88), en la medida en que ambas cosas requeririan trascender la ética del semejante.

En efecto, no parece que la solución esté simplemente en respetar al otro, al diferente. guiado por la voluntad de no hacer al otro lo que no quieras para ti, sino en asumir que el otro distinto a mí desea y tiene derecho a vivir su vida y a mantener sus discursos tanto como yo. La tolerancia requiere un espacio donde sea posible mantener una sabiduría ecológica (una ecosofía, sostiene MAILLARD, 2018, p. 68); es decir, un espacio para el entendimiento de la interrelación entre todos los seres vivos.

En lo que respecta a la realidad brasileña, la antropóloga e historiadora Lilia Schwarcz (2019, p. 208) cuestiona el mito de que el brasileño sea tolerante y pacifico, al mostrar a través de hechos históricos procesos de borrado de diferentes culturas, observables, desde la época colonial, en tratados, cartas y otros documentos de los siglos XVI y XVII. La dureza de la convivencia se constata, por ejemplo, en el intento de aniquilar a los pueblos indigenas, por un lado, y en los discursos de justificación de la dominación necesaria, por el otro. La negación de la violencia y la intolerancia hacia el otro, el diferente, según sostiene la mencionada historiadora (Ibid, p. 210), busca encubrir y minimizar los problemas nacionales, como es el caso de la esclavitud y la dictadura militar, que algunos calificaron de racismo "menos perverso" y de dictadura "blanda" (Dictablanda), incluso a pesar de que los datos objetivos revelan todo lo contrario (Ibid, p. 210).

Brasil es mucho más exclusivo que inclusivo, continúa argumentando Schwarcz, y, al silenciar ambivalencias y contradicciones, parece demostrar que prefiere dejar en lo invisible aquello que, sin embargo, se mantiene presente en la superficie (SCHWARCZ, 2019, p. 210). El abuso de negros y empleados de grandes propiedades rurales privadas, a lo largo de la historia, preserva y reitera la desigualdad social, la discriminación racial y de género. Aunque estas prácticas no justifican completamente la situación del presente, sin embargo, ayudan, objeta Schwarcz, a iluminar la escena actual, al responder a una misma lógica, pero ahora debidamente invertida (/bid, p. 211). ${ }^{8}$ En lugar del "ritual de tolerancia", añade, actualmente se practica la confrontación y la expresión abierta de la polaridad, sin ocultarlas, sin silenciarlas. La lógica de "ellos contra nosotros" y "nosotros contra ellos" opone a un "ellos" (vagos, corruptos, ladrones, ideólogos, personas sin escrúpulos, parásitos) y a un "nosotros", ubicados en el otro lado de la polaridad (Ibid, p. 212). Esta lógica binaria conlleva también, según esta misma historiadora (Ibid, p. 212), narrativas binarias que

8 Feré (2018, p. s84), refiriéndose a la estigmatización de los negros en Brasil, observa que hay una construcción y reproducción de estereotipos discriminatorios que resultan de un proceso de despersonalización, en el que el sujeto, cuanto más oscura es su piel, más se estigmatiza y más se ve privado de su identidad individual, aniquilada por el estereotipo generalizado asociado con el color de la piel. 
relatan una relación de odio y afecto, entre "grupos familiares honestos" frente a otros "corruptos" o, dicho de otro modo, narrativas de buenos frente a malos, de colectivos frente a individuos solitarios, degenerados y, en fin, de quienes se identifican con una determinada religión frente a los agnósticos y sin creencias.

En este sentido, el contexto de las redes sociales favorece sin duda la agudización de las polarizaciones, ya que, como asegura Schwarcz, no hay tiempo para la confirmación de hechos, documentos y fuentes, ni para la autoria intelectual, o para un análisis menos pasional que el que se hace en el calor del momento (Ibid, p. 213). Lo que se percibe, de esta manera, es la promoción de narrativas políticas creibles, distopías funcionales, con un lenguaje simplificado, breve y directo, dirigido a "un buen enemigo", que puede ser el objeto de mucha ira y oposición, incluso tratándose de una realidad creada con llamamientos explícitos a las emociones destinados a reforzar la división entre "nosotros" y "ellos".

Esta oposición, como lo explica Schwarcz (2019, p. 214), no es exclusiva de Internet ni del nacionalismo brasileño. Es una caracteristica común de los discursos autoritarios, que fomentan el prejuicio y la intolerancia contra las opiniones, creencias, valores u opciones sexuales, difundiendo estereotipos para afirmarse. El aumento de la intolerancia: racismo, sexismo, misoginia, antisemitismo, homofobia, etc. muestra la crisis de la democracia, ya que afecta a la libertad y la igualdad en un estado regular de derechos. En Brasil, la intolerancia tiene sus raices en el pasado, a pesar de la persistente negación del conflicto, y gana terreno con la larga crisis iniciada en 2013 e instalada en 2014 y con la consiguiente recesión que impactó en la disminución de los ingresos, el aumento del desempleo y la aversión, en diferentes niveles, respecto a la corrupción, la inseguridad, el crimen organizado, la desorganización del Estado, así como respecto a los intelectuales, a los nuevos actores políticos y, en fin, a todo lo que no nos 'concierne' o no nos 'representa' (Ibid, p. 215216). Tal aversión desordenada no se centró, sin embargo, contra el racismo, el feminicidio, los crímenes de género o la dictadura militar, destaca la citada historiadora (/bid, p. 215-216), lo que terminó revelando la fragilidad de la joven democracia frente a una sociedad dividida entre los valores progresistas, atentos a los derechos humanos y los valores conservadores.

En este escenario, se cuestiona el papel y la credibilidad de quienes detentan el poder. Una nueva distopía, en palabras de Schwarcz (2019, p. 217), promueve la creación de una especie de "incredulidad generalizada", que no reconoce ningún valor excepto el cobro de todo lo que fue 'sustraído' a los ciudadanos, generando más intolerancia, intransigencia y falta de respeto por las diferencias. Este problema alcanza grandes proporciones con la destitución de la presidenta Dilma Rousseff, en 2016, que desbloqueó el crisol de resentimientos y dio como resultado una política deliberada de odio y polarización, visible en el

\begin{abstract}
aumento da violência contra a comunidade LGBTTQ, as reações à inclusão de deficientes na sociedade, as manifestações xenófobas contra imigrantes e estrangeiros, os casos de bullying em escolas e ambientes de trabalho, gerados por diferenças raciais, de gênero ou até mesmo divergências politicas, assim como têm se multiplicado os ataques a terreiros de candomblé (SCHWARCZ, 2019, p. 217-218).9
\end{abstract}

Con el aumento de la crispación social, la intolerancia contra Rousseff, que estaba relativamente inactiva en las primeras elecciones en 2010, y que habia cobrado impulso en las elecciones de 2014, empeora en 2015 y en 2016. durante el proceso de impeachment, momento en que surgen ataques machistas, misóginos, contra la presidenta, a veces disimulados bajo distintos ropajes, a veces vinculados a noticias falsas; en cualquier caso con una amplia y rápida circulación en los medios de comunicación, sin la correspondiente asunción de responsabilidades

9 "el aumento de la violencia contra la comunidad LGBTTQ, las reacciones a la inclusión de personas con discapacidad en la sociedad, las manifestaciones xenófobas contra inmigrantes y extranjeros, los casos de bullying en las escuelas y entornos laborales, generados por diferencias raciales, de género o incluso políticas, así como se han multiplicado los ataques a los templos de Candomblé (SCHWARCZ, 2019, p. 217-218)." [la traducción al español es nuestra] 
por parte de los autores y difusores. Tales precisiones nos parecen importantes para comprender, por un lado, el funcionamiento de los discursos intolerantes y, por otro lado, el discurso intolerante contra Rousseff en algunos de los grandes medios de comunicación brasileños.

\section{¿Cómo estudiar los discursos intolerantes?}

Al estar situados en tal interfaz entre lo biológico y lo socio-cultural y económico, creemos que el odio y la intolerancia son objetos de estudio dificilmente abarcables desde una sola disciplina. Su comprensión requiere una aproximación pluridisciplinar e interdisciplinar.

En concreto, en el ámbito de las ciencias del lenguaje, está la dificultad añadida de que las emociones raras veces se verbalizan y, cuando es así, muy raramente se expresan de forma explícita y, menos veces aún, se estudian en su relación con la argumentación ${ }^{10}$, a pesar de su importancia en la dinámica social de las interacciones lingüisticas.

En efecto, sabemos que el discurso de odio o intolerante raras veces se manifiesta con marcas especificas distintas de un discurso "normal" socialmente aceptable, precisamente para evitar sanciones o algún castigo impuesto por las autoridades competentes. Y a pesar de que existe, en el sistema de cada lengua, un léxico variadisimo para nombrar las emociones ${ }^{11}$, estas no suelen manifestarse explícitamente usando el vocabulario disponible, sino a través de enunciados con "tonos" intolerantes (ver más abajo), que comportan implícitos (presupuestos e implicaciones), desencadenando inferencias por defecto (implicaturas conversacionales generalizadas ${ }^{12}$ ), estereotípicas, presumibles (LEVINSON, 2000), no evaluables como verdaderas o falsas, sino como acordes con representaciones colectivas o sociales fijadas acerca de la realidad extralingüistica y de las costumbres discursivas.

Nosotros entendemos que esto es lo que hace que los discursos intolerantes se propaguen tanto y tan fácilmente, dado que parecen inofensivos porque resultan discursos archiconocidos y generan una confianza basada en la cultura de una colectividad, en los usos y los saberes comunes y, en fin, en las ideologias y las mitologias compartidas por una comunidad discursiva. ${ }^{13}$

En resumidas cuentas, la intolerancia no usa abiertamente el léxico de la intolerancia, sino al contrario se suele manifestar con palabras imprecisas, subdeterminadas (FUCHS, 2008), que no comprometen la cara ${ }^{14}$ (GOFFMANN, 1955) del locutor y que no requieren ser completadas semánticamente con ayuda del contexto sino simplemente sintonizadas con un estado de cosas (una determinada conformidad con la memoria de los usos, o con el saber colectivo en situaciones semejantes ${ }^{15}$ ). O, por decirlo de otro modo, la intolerancia se suele manifestar con palabras cuya interpretación no depende de la situación de enunciación sino de la conformidad respecto a lo que Récanati (2001) llama las situacionesfuente (situations-sources ${ }^{16}$ ).

\footnotetext{
10 Con algunas honrosas excepciones, como el número 8 | 2012 de la revista Argumentation et Analyse du Discours dedicado al "Insulte, violence verbale, argumentation", bajo la dirección de Laurence Rosier (https://journals.openedition.org/aad/1242).

11 En nuestro texto anterior, López-Muñoz \& Cappponi (2017), citado al inicio del presente trabajo, resaltábamos la existencia, sólo para el español, de más de 50 sinónimos solo para el concepto de odio.

12 Las implicaciones conversacionales generalizadas dependen directamente de las convenciones sociales, convenciones de uso habitual, rutinario (REYES, 2018, p. 193-203). Se trata de inferencias que podriamos llamar "listas-para-inferir", en el sentido en que, en vez de hacer cálculos personales, al interlocutor le resulta más cómodo servirse de inferencias ya hechas en situaciones similares.

${ }_{13}$ No es una división estricta de la realidad social, sino una noción que sirve para caracterizar el discurso como una práctica social, incluyendo las prácticas sociales que presuponen y engendran normas de intercambio, los valores cognitivos que impregnan (y construyen) las producciones lingüisticas basadas en tales prácticas y, en fin, los valores pragmáticos relacionados con la interacción social y, en consecuencia, la dimensión retórica de las producciones lingüísticas (véase BERNIER, 1999).

14 Según Goffman (1955), la cara es la imagen pública positiva que cada hablante busca establecer en sus interacciones sociales.

15 Tal saber colectivo, se situaría en un estrato pre-enciclopédico, en un nivel de inconsciente colectivo (o ça anthropologique) en la terminología de Durand (1969).

16 Récanati (2001) defiende la idea de la su determinación generalizada de los enunciados. Las palabras no tienen significación lingüística por sí mismas, sino que la adquieren en situación de enunciación. Es en el uso concreto (situation-cible, experiencia presente, situación de empleo) donde se determina la significación de las palabras o expresiones, así como las condiciones de verdad del enunciado, a través de dos procesos que operan más o menos simultáneamente: uno "referencialista" (las condiciones de verdad se deciden en contexto una vez atribuidos los referentes concretos), otro "eliminativista" (las condiciones de verdad se deciden en función de la conformidad de la situation-cible con respecto a las situations-sources (estas pueden entenderse/recordarse singularmente o como conjunto, como representación más o menos esquemática de las experiencias pasadas).
} 
Así, los discursos intolerantes no se sustentan sobre una gramática o un léxico de la intolerancia, sino sobre una doxa, sobre verdades siempre y todavía pendientes de ratificación. Siendo así, creemos oportuno traer a este punto del debate las características de los discursos intolerantes planteados por la experta en semiótica y analista del discurso Diana Pessoa de Barros (2015, p. 63-64), quien advierte sobre una 'organización narrativa' basada, sobre todo, en un discurso de sanción a sujetos considerados malos cumplidores de ciertos contratos sociales: blanqueamiento de la sociedad, pureza del lenguaje, heterosexualidad y otros. En cuanto a las modalizaciones discursivas, la citada analista sostiene que los discursos intolerantes son muy apasionados, predominando particularmente en ellos las pasiones malévolas (antipatía, odio, ira, xenofobia, etc.) que buscan dañar al sujeto que no ha cumplido los acuerdos sociales, así como las pasiones del miedo al "diferente", por el daño que este podria llegar a hacer. La autora entiende (Ibid, p. 63-64) que existe una complementación entre las pasiones malévolas del odio al diferente y las pasiones benévolas de amor por los 'iguales' (el tema del amor por la patria, su propio idioma, su propio grupo étnico, su propio color, etc.).

Barros (2015, p. 64) destaca dos etapas: (a) la del prejuicio, en la que el sujeto demuestra mala intención respecto al otro (el diferente), al tiempo que es benevolente con su patria y sus iguales; (b) la de la intolerancia propiamente dicha, fase en la que el sujeto, impulsado por sus prejuicios, pasa a la acción, es decir, actúa contra el otro, al que considera la causa de sus pérdidas. Dicho brevemente, en términos de ámbitos temáticos, el "diferente" es considerado aquel que rompe los pactos y acuerdos sociales, por no ser humano, por ser contrario a lo natural, por estar enfermo y sin ética o estética, razones por las cuales es temido, odiado, sancionado negativamente y castigado (Ibid, p. 65). Podemos entender, de acuerdo con Barros (Ibid, p. 65), que este "diferente" puede ser atacado mediante diversas materializaciones discursivas, las cuales que requieren por ello un análisis basado en teorias que favorezcan un mejor entendimiento del problema en la base.
Con este fin, agregamos a la presente discusión reflexiones basadas en la perspectiva dialógica del discurso del círculo de Bajtín, para quien el signo ideológico está constituido por el horizonte social de una época y de un grupo social que le concede un determinado valor (VOLÓCHINOV, 2017. p. 110). El signo ideológico, verbal y no verbal, implica el cruce de énfasis valorativos con múltiples direcciones en un escenario de lucha de clases. Por esta razón, cualquier palabra discriminadora o amenazante puede convertirse en un cumplido, igual que cualquier verdad puede sonar inevitablemente como una gran mentira para muchos (Ibid, p. 113). Esta dialéctica interna del signo, importante para analizar el discurso intolerante, requiere que los investigadores observemos los índices de valoración que emergen en la compleja dialogicidad del discurso, es decir, en el conjunto de relaciones que los signos (verbales o no verbales) contienen y engendran.

Así, en cada enunciado concreto, que se instaura en el heterodiscurso dialogizado (diversidad de voces en tensión), hay un cruce de fuerzas tanto centripetas (centralizadoras) como centrifugas (descentralizadoras) (BAKHTIN, 2015, p. 42). El discurso, al entrar en un medio de valoraciones $y$ acentos ajenos, dialógicamente agitado y tenso, establece relaciones complejas con los restantes discursos, anteriores y posteriores, de tal forma que se fusiona con unos mientras se distancia de los otros y se cruza con terceros, sin poder dejar de ser un participante activo en el diálogo social (Ibid, p. 47-48). Dicho de otro modo, en la cadena de comunicación discursiva, cada discurso responde a los enunciados ya pronunciados y anticipa las respuestas, lo que implica no solo una dialogicidad interna sino también una maraña de relaciones, no siempre aparentes.

La palabra (el enunciado, el discurso), como lo observó Bakhtin (2003), está constituida por un tono emotivo-volitivo, expresado por la entonación expresiva, el acento de valor, que marca la actitud del sujeto a la vez hacia el objeto de su discurso y hacia su interlocutor, y marca también la relación entre lo dicho y lo tácito, entre lo verbal y lo no verbal. El tono, desde esta perspectiva, da color a la palabra al mismo tiempo 
que indica que la palabra es solo un apéndice de otra presencia (MEDVIÉDEV, 2012, p. 185, p. 190), es decir, la palabra tiene una memoria, está vinculada a su contexto sociohistórico, a otros enunciados y a juicios sociales de valor.

Dicho lo anterior, en los análisis, observamos tonos intolerantes en la dialogicidad del discurso con respecto a las posiciones tomadas, en vista de la confrontación de los índices sociales de valoración. De esta manera, se destacan aspectos intolerantes del discurso, a través de la dialéctica del signo ideológico, que no solo refleja (reiteración) sino que también refracta (expansión) valores que, en el entramado dialógico, buscan descalificar o incluso excluir al otro de la vida social.

Pasemos a la siguiente sección, que aborda cuestiones metodológicas y analiticas.

\section{¿Cómo se manifiestan los tonos intolerantes en los discursos de los grandes medios de comunicación?}

Partimos, para intentar responder a esta pregunta, de algunos análisis realizados en una investigación anterior con el título de Ethos e ato ético: o discurso intolerante e a politica brasileira em redes (sociais) de sentidos (DI FANTI, 2019), donde mostramos la progresión de los índices de intolerancia en la materialización de los discursos mediáticos a lo largo de los tres momentos de la vida política de Rousseff: primera elección (2010), segunda elección (2014) e impeachment (2015-2016). ${ }^{17}$

Para el presente artículo, retomamos en concreto nuestro análisis de las portadas de la revista Isto $\dot{E}$, del 06/04/2016, y del periódico Folha de S. Paulo, del 02/05/2016, buscando centrar nuestra atención en el hecho de que no se espera que los principales medios de comunicación, independientemente del momento histórico-social, usen tonos intolerantes para posicionarse respecto al presidente de la república, sobre todo teniendo en cuenta de que este no pertenece, en principio, a ninguno de los grupos convencionalmente considerados víctimas potenciales de los discursos intolerantes. ${ }^{18}$

Las portadas seleccionadas circularon en un momento en que la sociedad, bastante polarizada, seguía con fervor los debates, tomando posiciones sobre el posible impeachment a la presidenta Dilma Rousseff, antes y después de que este fuera votado en la Cámara de los Diputados el 17 de abril y en el Senado Federal el 31 agosto de 2016. Pretendemos demostrar que el material seleccionado es representativo de la manera en que ciertas manifestaciones intolerantes son transmitidas por los medios de comunicación, disimuladas bajo forma de información y / u opinión o, por decirlo de otro modo, como lo observa Charaudeau (2016, p. 49), transmitidas bajo forma de palabra colectiva con el objetivo de influir, directa o indirectamente, en la construcción de la opinión pública en momentos políticos decisivos, como en el caso concreto que nos ocupa.

El análisis, que se centra en la constitución dialógica de los tonos intolerantes, en diferentes materializaciones, a partir de dos enunciados verbo-visuales, considera la dialéctica de los signos ideológicos, la pluralidad de voces, el diálogo entre discursos, las posiciones axiológicas asumidas y el contexto socio-histórico. Está organizado en tres partes. En la primera, analizamos la portada de la revista Isto $\dot{E} ;$ a continuación, analizamos la portada de Folha de S. Paulo; y, finalmente, presentamos una reflexión acerca del conjunto de ambos análisis efectuados.

Comenzamos, pues, con el siguiente documento:

\footnotetext{
17 El proceso de impeachment (juicio político) fue provocado por una denuncia de un delito de responsabilidad contra la presidenta Dilma Rousseff y se procesó en la Cámara de Diputados y el Senado Federal. La Cámara aceptó la apertura del proceso de impeachment el 2 de diciembre de 2015 y este fue aprobado por el plenario el 17 de abril de 2016. A partir del 12 de mayo, el caso se abrió en el Senado. y la presidenta fue destituida provisionalmente a la espera de la conclusión del proceso, que culminó efectivamente con su destitución definitiva el 31 de agosto de 2016. Aunque destituida de su cargo, Rousseff no perdió de facto sus derechos politicos, lo que le permitió concurrir para el Senado de Minas Gerais en las elecciones de 2018.

18 Entendemos que la revista semanal Isto É y el diario Folha de S. Paulo son suficientemente reconocidos en la sociedad brasileña y son suficientemente representativos de los grandes medios de comunicación de Brasil.
} 
Figura 1 - As explosões nervosas da presidente

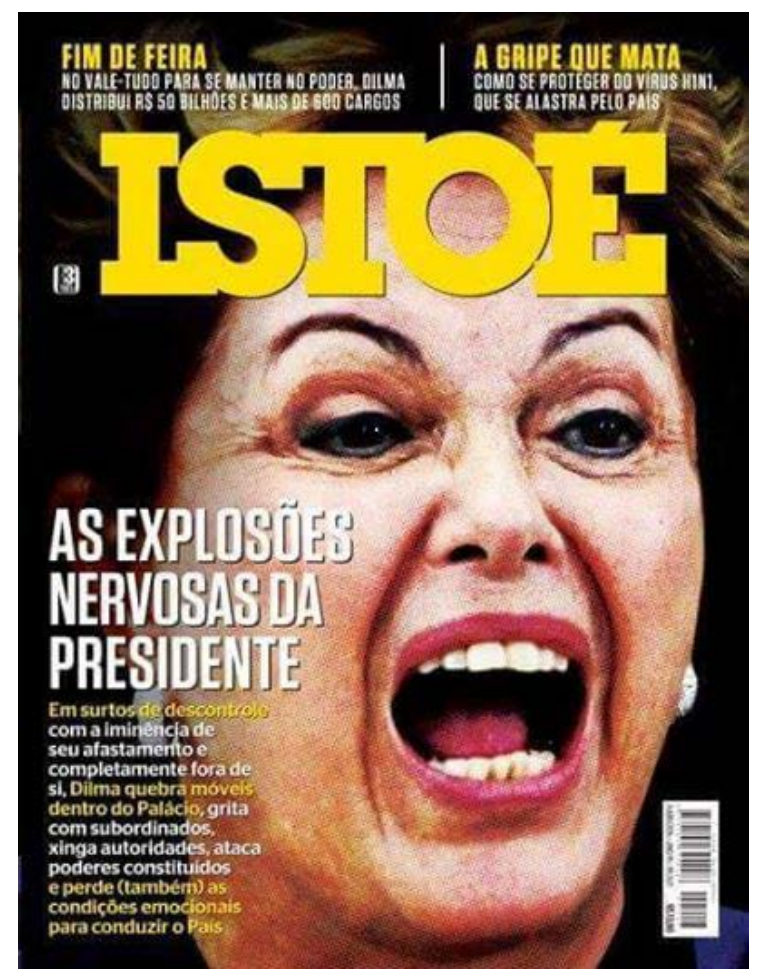

Isto É - 06/04/2016 19

La portada de la revista Isto $\dot{E}$, fechada el 06/04/2016, causó una gran repercusión en la sociedad en general y en las redes sociales en particular al haberse enfocado, de manera tan apasionada y apelativa, en la supuesta falta de control emocional de la presidenta Dilma Rousseff dias antes de su juicio político en la Cámara de Diputados. La portada presenta tres titulares, dos de los cuales (uno secundario y uno principal) se refieren a la presidenta con los enunciados "Fim de feira ${ }^{20 "}$ y "as explosões nervosas da presidente ${ }^{21 "}$, además de un tercer titular (secundario), "A gripe que mata", referido a la epidemia causada por el virus $\mathrm{H}_{1} \mathrm{~N} 1$.

Al poner en relación dialógica los titulares secundarios con el principal, podemos percibir, por un lado, que hay, en todos ellos, una orientación evaluativa que señala situaciones de conflicto, problemas que la sociedad debe enfrentar, como se ve por los signos ideológicos usados: "Fin", "mata", "explosiones nerviosas". Por otro lado, es evidente que la carga negativa de esos signos recae sobre la presidenta, siendo de tal forma que dos de los tres informan directamente sobre Rousseff. Las llamadas secundarias, a pesar de que tienen un tono pretendidamente más informativo, en comparación con el tono del titular principal, presentan ciertas diferencias que destacamos a continuación:

(a) "FIM DA FEIRA - En el todo-vale ("vale-tudo") para permanecer en el poder, Dilma distribuye ("distribui") 50 mil millones de reales (R\$) y 500 cargos" (titular secundario - Dilma Rousseff).

(b) "A GRIPE QUE MATA - Cómo protegerse del virus $\mathrm{H}_{1} \mathrm{~N}_{1}$, que se propaga por todo el país" (titular secundario - Gripe causada por el H1N1).

Mientras que en (a) los signos presentan refracciones destinadas a descalificar a Rousseff respecto a su papel en el gobierno, como es el caso de "feira" (mercadeo, trueque), "vale-tudo" (transacciones sin criterios) y "distribui" (compra de apoyos), en (b) los signos tienen un mayor indice de reflejos, dado que se refieren a la gripe ("protegerse" y "propagarse"). Con respecto al titular principal, que motivó la selección de esta portada, podemos observar mediante el análisis de los enunciados, en su constitución verbo-visual, tonos intolerantes contra Rousseff, presentes en la expresión "AS EXPLOSÕES NERVOSAS DA PRESIDENTE", en letras mayúsculas grandes, blancas, en primer plano, asociadas con la fotografia de la presidenta, en el fondo, pero con gran alcance y reclamo visual. La dialéctica del signo, al reflejar o refractar determinados sentidos, refleja una imagen de la presidenta, pero sobre todo refracta una imagen manipulada e hiperbolizada de esta. Cabe destacar que la foto fue sacada de su contexto original, habiendo sido tomada durante un partido de fútbol de la Copa del Mundo celebrado en Brasil (en el momento en que la presidenta celebraba un gol de Brasil). Centrada en un fondo negro, la imagen saturada (con una gran pigmentación como si saliera de la revista) presenta tonos valorativos de una presidenta

9 [https://istoe.com.br/edicao/894_AS+EXPLOSOES+NERVOSAS+DA+PRESIDENTE/] Consultado en mayo de 2018.

20 "Fin del mercado" para hacer referencia a la mezcla desordenada de restos que caracteriza el final del dia de mercado ltraducción y nota de los autores de este artículo].

21 "Los arrebatos nerviosos de la presidenta" [la traducción es nuestral. 
desequilibrada, con "arrebatos nerviosos", como puede verse por la expresión alterada: la boca abierta, los dientes blancos proyectados adelante, lengua afuera, ojos entrecerrados.

Al observar el heterodiscurso dialogizado en el que se confrontan fuerzas centripetas y centrifugas acerca dela situación política de la presidenta Dilma Rousseff, ante la inminencia de la destitución de esta, percibimos, en la portada analizada, un conjunto de voces que, aliadas con los defensores de la aprobación del impeachment, revelan un movimiento centralizador, autoritario, que no solo descalifica a la persona diferente, que sería una amenaza para el sujeto intolerante, sino que también incita al odio, al desprecio y a la falta de respeto hacia ese ser anatematizado. En este ámbito, los tonos intolerantes sexistas, engendrados en los enunciados verbo-visuales, se dirigen a la presidenta, revelando, por un lado, las posiciones axiológicas asumidas por la revista al denunciar el desequilibrio emocional de la presidenta y, por otro, calificando, a través un diálogo tenso de voces, el equilibrio y la moderación del vicepresidente, Michel Temer. Siguiendo con el titular principal, "AS EXPLOSÕES NERVOSAS DA PRESIDENTE", encontramos, en letras más pequeñas, alternando entre letras amarillas y blancas, una selección de palabras cargadas de tonos evaluativos que desacreditan la aptitud de Rousseff para continuar ocupando el cargo de primer presidente del pais: una persona con un visible brote de falta de control ante la inminencia de su destitución ("surto de descontrole com a iminência de seu afastamento"), completamente fuera de si ("completamente fora de si"), una gamberra que rompe el mobiliario ("quebra móveis"), que grita a sus subordinados ("grita com subordinados") y ofende a las autoridades ("xinga autoridades"), atacando a los poderes constituidos ("ataca poderes constituídos"), y careciendo en fin (también) de las condiciones emocionales necesarias para liderar el pais".

En el tejido dialógico del discurso analizado, es posible percibir una dramatización exacerbada, basada en un lenguaje plurisemiótico atractivo, que destaca lo que sería un temperamento demasiado amenazante de la presidenta como para poder permanecer en el poder. Esta sobredramatización, según Charaudeau (2016, p. 121), puede explicarse como una caracteristica del discurso informativo de los medios en la manera de informar y comentar acontecimientos, con el objetivo de atraer al público y generar impacto emocional. Esto se agrava cuando observamos estos efectos dramáticos en las portadas de revistas y periódicos de algunos grandes medios de comunicación, que circulan no solo en formato impreso, sino también digitalmente, en Internet y en las redes sociales, con amplia frecuencia de reproducción.

Los tonos de intolerancia en la portada analizada nos permiten calificarla como un discurso intolerante concibiendo este, como vimos en Barros (2015), por la manera en que está organizado para castigar a los sujetos que no cumplen el contrato social esperado. En el caso que nos ocupa, el castigo estaría destinado a la presidenta, por no presentar el equilibrio emocional requerido para liderar el país, como se puede ver por el tono expresivo de los enunciados que apuntan al carácter patológico de la diferencia, a la falta de salud mental ("explosões nervosas", "surto de descontrole", "fora de si" "[perdal das condições emocionais"), en oposición a las cualidades de equilibro y salud normalmente requeridas. El tema de la salud mental se reitera en el reportaje interno de la revista, en enunciados destacados: Dilma, bajo el efecto de Rivotril, rompe muebles y procesa a Isto É ("Dilma, sob efeito de Rivotril, quebra móveis e processa Isto É") y "Fuera de control" ("Fora do controle")22.

En la lógica de "nosotros" contra "ellos", la revista Isto É se alia abiertamente con los adeptos del impeachment, mostrando, a través de tonos intolerantes, la incapacidad de la presidenta para continuar su mandato. En el juego de palabras e imágenes, parece que el otro (la otra) es juzgado (juzgada) negativamente, ya que constituye una

22 Rivotril es un medicamento ansiolítico, vendido exclusivamente con receta médica, y tiene la función de reducir la excitación, la ansiedad y la agitación. 
amenaza para la supervivencia de "nosotros". Esta interpretación, basándonos en Charaudeau (2016, p. 25), alerta sobre la forma en la que el otro es caricaturizado, protegiendo la cara de sus propios compañeros. En este espacio surge la estereotipificación que, según Amossy (2015, p. 46), revela efectos nocivos al juzgar a un individuo reducido a una imagen simplificada, cuando no abiertamente falsa, lo que lleva a la discriminación. En el presente caso, el estereotipo de la persona emocionalmente desequilibrada, asociado con el tema de género, potencia y fortalece un rumor colectivo intolerante contra Rousseff como presidenta de Brasil, en su condición de mujer, agravando su situación frente a la opinión pública durante el proceso de juicio político.

Pasemos a la portada del periódico Folha de S. Paulo.

Figura 2 - La Presidenta Dilma Rousseff es perturbada por una mosca

\section{FOLHA DE S.PAULO}

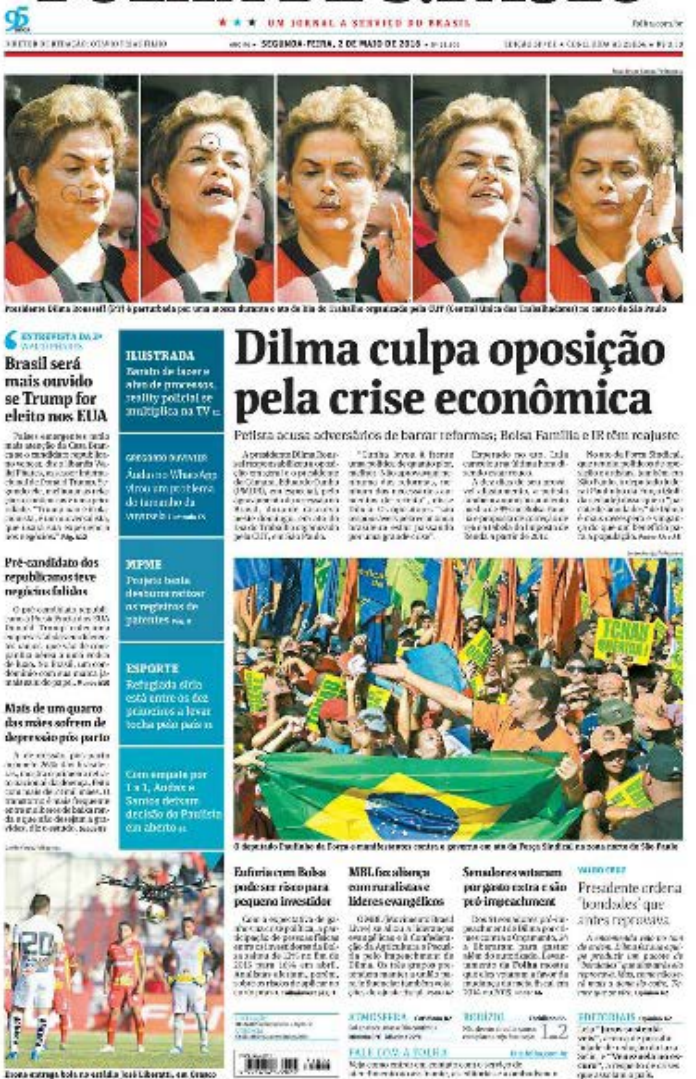

Folha de S. Paulo - 02/05/2016 23
A diferencia de lo que observamos en la revista Isto É y partiendo de las divergencias entre el proyecto enunciativo y la construcción discursiva de las portadas de los diarios y de las revistas semanales, los tonos intolerantes que se destacan en la portada del periódico Folha de S. Paulo, del 02/05/2016, surgen de la articulación entre la secuencia de las cinco fotos de la presidenta Dilma Rousseff, que ocupa toda la extensión horizontal de la primera línea del periódico, y la leyenda de las fotos: "La presidenta Dilma Rousseff (PT) es perturbada por una mosca durante el acto del Día del Trabajo organizado por la CUT (Central Única de los Trabajadores) en el centro de São Paulo ".

La construcción del enunciado verbo-visual, al resaltar los gestos de la presidenta, grabados en la secuencia de las fotos, defendiéndose de una mosca, reitera el desequilibrio emocional de Rousseff observado en la portada de Isto É. Mientras que en la revista el desequilibrio está abiertamente relacionado con la incapacidad emocional de la presidenta para permanecer en el gobierno, en el periódico el desequilibrio, en una primera lectura, se asocia con el hecho de que la presidenta no mantiene el control ni siquiera cuando se trata de evitar que una mosca la hostigue durante un acto público.

El hecho de que un insecto perturbe a una persona es trivial, ya que esto le puede pasar a cualquier ser humano. Lo que no es trivial es que ese hecho se convierta en materia de portada de un importante periódico.

El signo ideológico de la mosca en este contexto refleja, por un lado, la molestia de la mosca cuando se posa en diferentes lugares, marcados con un círculo en cada foto, lado derecho de la cara (cerca de la boca), frente, labio superior, punta de la nariz y lado izquierdo de la cara. Por otro lado, este signo refracta el objetivo, estropeándolo, deteriorándolo, ya que sabemos que las moscas son generalmente atraídas por el olor a detritos y a materia orgánica en descomposición. En esta construcción dialógica, los tonos intolerantes

${ }_{23}$ Ihttps://acervo.folha.com.br/leitor.do? numero=20578\&anchor=6022744\&origem=buscalConsultado en mayo de 2018 
revelan la posición axiológica de Folha de S. Paulo en relación con la presidenta, quien, en medio del heterodiscurso dialogizado señala la fragilidad de Rousseff frente a los impasses.

También pensamos que podria reflejary refractar alguna forma de amenaza por parte de colectivos que operan de forma discreta e insistente, tal como hacen las moscas, a modo de aviso de su intención vehemente de participación en el proceso inminente de descomposición de algo.

Observando la construcción verbo-visual más amplia de la portada, percibimos, en términos de fotografias, tres momentos: el primero, resaltado, ya mencionado, es la secuencia de fotos de la presidenta; la segunda, igualmente prominente y más centralizada, es un registro fotográfico de una manifestación a favor de la destitución, cuya leyenda dice: "O deputado Paulinho da Força e manifestantes contra o governo em ato da Força Sindical na zona norte de São Paulo" (El Diputado Paulinho da Força y manifestantes contra el gobierno en un acto de la Fuerza Sindical en la zona norte de São Paulo); y el tercer momento es una pequeña fotografia, en comparación con las otras, una cuestión aparentemente secundaria, relacionada con el deporte, cuyo texto al pie dice: "Drone entrega bola no estádio José Liberatti, em Osasco" (Dron entrega la pelota en el estadio José Liberatti, en Osasco). De las tres imágenes que componen la portada, las dos principales, la secuencia de fotos y la imagen de la manifestación, conciernen directamente a Rousseff, lo que manifiesta el posicionamiento del periódico a favor de la destitución de la presidenta. La imagen de la manifestación de Força Sindical, aunque en principio pueda parecer desconectada con lo anterior, está asociada con el titular principal, que, en términos verbo-visuales, abarca un lugar privilegiado y de grandes proporciones en la portada. En términos de la constitución verbal de los titulares, el principal "Dilma culpa oposição pela crise econômica" (Dilma culpa a la oposición por la crisis económica), con letras grandes resaltadas en dos lineas, y una secundaria: "Presidente ordena 'bondades' que antes reprovava" ("La presidenta da por bueno lo que antes reprobaba"), con letras destacadas, involucran directamente a la presidenta.

Estableciendo una relación dialógica entre el enunciado verbo-visual de las fotos secuenciales que evoca tonos intolerantes y el titular principal de la portada ("Dilma culpa a la oposición por la crisis económica") seguido del registro fotográfico de la manifestación favorable a la destitución de la presidenta, podemos percibir los efectos de los sentidos generados, en diferentes dimensiones.

La primera conclusión que se deduce del diálogo con el titular es que una mujer "perturbada" (se vuelve a evidenciar la cuestión de género observada en el análisis de la portada de la revista), no tendría legitimidad para culpar a nadie y, por lo tanto, concretamente, no podría culpar a la oposición por la crisis económica.

En términos lingüísticos, percibimos la diferencia entre la voz pasiva en el subtitulo de las fotos secuenciales de Rousseff: "Presidente Dilma Rousseff (PT) é perturbada por uma mosca..." y la voz activa en el título principal de la portada ("Dilma culpa oposição...") así como en el título secundario ya resaltado ("Presidente ordena 'bondades'..."). Entendemos que este recurso lingüístico indica, en el tejido dialógico del discurso, que, en voz pasiva, quien actúa es la mosca contra la presidenta, es decir, Rousseff sufre la acción, mientras que enunciativamente pone de relieve la impotencia e "incapacidad" de reacción de esta frente al insecto. En la voz activa, quien practica la acción es la presidenta, pero la acción es valorada negativamente, de manera que la descalifica enunciativamente.

La segunda observación se refiere al diálogo entre los dos principales registros fotográficos. Como signo ideológico, la fotografía de Rousseff, continuando la reflexión ya desarrollada, no solo muestra a la presidenta en una situación en la que una mosca se posa en diferentes partes de su rostro, sino que sobre todo refracta la figura de una presidenta desestabilizada, al imprimir acentos de valoración que se pueden percibir en los enfoques fotográficos sobre la cara de la presidenta, destacando trazos caricaturescos sobre un fondo 
difuso, marcas de envejecimiento (arrugas en los ojos, boca, frente, manos), dejadez (cabello reseco) y, en definitiva, la falta de compostura en público (en el acto del Día del Trabajo) además del uso de ropa roja (en referencia al Partido de los Trabajadores (PT) y sus seguidores). Estas caracteristicas, vinculadas a los estereotipos de género y hechas extensivas al partido político, contribuyen a construir una imagen desgastada, descolocada, frágil y sin estabilidad emocional.

Ya en la demostración visual a favor del impeachment, el signo refleja una manifestación de Força Sindical con varias personas portando banderas y carteles, de tal manera que refracta, en el cruce de valoraciones, la fuerza y la unión del grupo contrario, tal como permite distinguir el enfoque centrado en el diputado federal Paulinho da Força junto con una gran cantidad de simpatizantes vestidos con los colores verde, amarillo, azul y naranja (Força Sindical). El uso del verde y el amarillo, reiterado por la bandera brasileña, redunda en los símbolos nacionales, así como, en el contexto sociohistórico actual, en la idea de oposición al PT.

El saludo de despedida "Tchau querida!" (iAdiós, querida!), impreso en los carteles, en la intersección de múltiples acentos, se remonta a un discurso entre el ex presidente Luiz Inácio Lula da Silva y su sucesora en el cargo, la presidenta Dilma Rousseff. Este discurso, publicado en la prensa, el 16/03/2016, en medio del proceso de destitución, de tal manera re-acentuado, comenzó a ser utilizado por los opositores al gobierno, marcando visiblemente el apoyo a la destitución de la presidenta.

En esta confrontación de enunciados plurisemióticos percibimos, en el diálogo tenso de diferentes voces, las valoraciones que se desprenden del tratamiento dado a los titulares, subtítulos e imágenes en la portada, evocando al unisono el posicionamiento axiológico del periódico a favor del impeachment, al tiempo que fomenta la división de "nosotros" y "ellos" (Ella). Así, los tonos intolerantes contra Rousseff resuenan en la articulación entre lo verbal, lo visual y lo extraverbal, lo dicho y lo no dicho, ya que los tonos, según lo observado por Volóchinov (2019, p. 123), son sociales por excelencia y sensibles a las oscilaciones del entorno social que rodea al hablante.

Pasemos a la reflexión del conjunto del material analizado.

A partir de los análisis realizados, observamos cómo los tonos intolerantes contra Dilma Rousseff se constituyen y engendran en ciertos enunciados verbales y visuales de grandes medios de comunicación brasileños con el fin de fomentar, en la dinámica generada entre fuerzas centripetas y centrifugas, voces que descalifican a la presidenta, frente a una diversidad de interlocutores (lectores e internautas), en el momento crucial de la votación de la destitución de la presidenta. En este escenario, percibimos que la intolerancia presenta, con diferentes grados de visibilidad, pautas machistas y misóginas, observables en la focalización sobre características habitualmente consideradas como "de mujeres", en tensión con las "de hombres", en un gesto a la vez de desacreditación de Dilma Rousseff y de deslegitimación las mujeres para presidir el país, apoyado en los estereotipos de falta de control emocional (en Isto É) y de excitabilidad (en Folha de S. Paulo).

En cuanto al hecho de que Dilma Rousseff sea el blanco del discurso intolerante por parte de los medios de comunicación, a pesar de que esta ocupe el cargo principal del ejecutivo por vías democráticas, entendemos que ello sería impensable en un momento de calma política, económica y social. Sin embargo, a partir de los análisis realizados, observamos que, del uso de los tonos intolerantes, fomentado por el inminente impeachment, puede deducirse inseparablemente, por un lado, la falta de argumentos consistentes y / o suficientes para apoyar la posición favorable a la destitución de la presidenta del gobierno y, por otro lado, una tentativa de ocultar la posición adoptada, apelando a estereotipos naturalizados socialmente y difundidos junto a noticias que pretenden ser imparciales. Lo que se percibe, en esta perspectiva, es que el discurso intolerante hace uso de estereotipos sexistas que permiten no criticar directamente el papel profesional 
desempeñado por Rousseff en el gobierno sino, a través de diferentes valoraciones intercaladas con complejas relaciones dialógicas, poner de relieve supuestas fragilidades de la presidenta como mujer (desequilibrio emocional y fácil excitabilidad) para hacer frente al desafio de gobernar un pais.

Tales consideraciones se refieren a la hegemonía de un modelo patriarcal, llamado por Gazalé (2019, p. 59) "sistema viriarcal" (destacando el concepto de virilidad sobre el de paternidad), que actúa como referencia para las relaciones humanas. En este sistema, al estar la mujer dotada de aptitudes "naturales" para el afecto, la servidumbre, la paciencia, la escucha y la dulzura, etc., no tendria la estabilidad emocional requerida para enfrentamientos y cargos de poder. El hombre, por su parte, teniendo como cualidades "naturales" la ambición, la competitividad, la movilidad, el carisma, la audacia, la autoridad, la combatividad, el gusto por el riesgo, estaría capacitado "naturalmente para los puestos de mando" (Ibid, p. 144). Por lo tanto, en la confrontación de voces, típica del heterodiscurso dialogizado, surge la discriminación de género, en la cual la intolerancia contra las mujeres se hace extensible a todas las personas consideradas "discapacitadas" (locos, personas funcionalmente diversas, enfermos), defendiendo la "figura del hombre sano y normal" en detrimento de la mujer $y$, en general, en detrimento de las personas con alguna discapacidad física, intelectual o sensorial. En resumidas cuentas, para los medios analizados, Rousseff no podría ocupar un puesto como presidente, dado que ello requeriría cualidades masculinas normales, las cuales tiene, como por casualidad, Michel Temer, a quien los mismos medios apoyan como sucesor natural en el contexto del impeachment.

Observamos, bajo este enfoque, el uso del discurso intolerante, basado en variadas marcas verbo-visuales, que, por un lado, llegan a la presidenta como una amenaza y, por otro lado, señalan un posicionamiento a favor de los defensores de la destitución de aquella, todo ello amplificado por el entrecruzamiento de los medios, la sociedad y la política. En efecto, como señala Charaudeau (2016, p. 68-69), el agente o el medio manipulador, cuando intenta incitar la aparición o el cambio de la opinión del público, no suele revelar de forma explícita su intención o su proyecto de influencia, sino que aprovecha una posición de legitimidad para construirse una identidad discursiva capaz de paralizar la opinión del otro o anular su credibilidad, ya sea por amenaza o por seducción, dramatizando su discurso de manera que consiga perturbar a la audiencia o incluso aterrorizarla, al mismo tiempo que silencia las voces disonantes, contestatarias, con el apoyo del grupo convocado a tal fin. ${ }^{24}$

Es por esto que muchos artículos de revistas y periódicos están sujetos a procesos judiciales. Tuvimos acceso a una de las sentencias publicadas por la revista Carta Maior25, el 18/07/2017, como resultado de una demanda interpuesta por Dilma Rousseff sobre el "derecho de respuesta" contra el reportaje de la portada de la revista Isto É, del 15 de julio de 2016, bajo el titulo: Regalias: coches oficiales al servicio de la familia de Dilma ("Mordomia: carros oficiais a serviço da familia de Dilma"). La sentencia, además de resaltar la protección legal del derecho de respuesta, señaló la virulencia del informe al contribuir ${ }^{26} \mathrm{al}$ clima inestable que ya imperaba en el Congreso Nacional, con la suspensión del mandato de la presidenta Dilma y la tramitación del proceso de impeachment instaurado por el Senado Federal en mayo de 2016. Entre los argumentos expuestos, la sentencia afirma que, de marzo a mayo de 2016, la revista Isto É publicó 11 números y "en todos ellos, sin interrupción, el nombre

\footnotetext{
24 Es importante tener en cuenta que, en general, quienes propagan la intolerancia no la reconocen y, a menudo, niegan su existencia porque creen que pueden controlar el significado de su discurso. Sin embargo, la forma de decir, como lo destaca Maingueneau (2018), revela una forma de ser que, por un lado, puede promover, sutilmente, identificaciones entre el hablante y el interlocutor y, por el otro lado, puede provocar distanciamiento y reacciones de repudio.

25 [https://www.cartamaior.com.br/?/Editoria/Politica/Dilma-vence-processo-contra-lsto-e-/4/38457] consultado en diciembre de 2018. 26 El texto original de la sentencia afirma que el texto de la mencionada revista contribuyó "para o clima instável que já percorria o Congresso Nacional, com a suspensão do mandato da Presidenta Dilma e a tramitação do processo de impeachment instaurado pelo Senado Federal em maio de 2016".
} 
y / o la foto de la presidenta se insertaron en la portada", terminando el año con un total de "DIECIOCHO 27 portadas utilizando el nombre y / o la imagen de la Presidenta". Estas informaciones apoyan nuestras reflexiones y abundan en las conclusiones de nuestro estudio acerca del uso de tonos intolerantes en la constitución del discurso por parte de los medios analizados. Concretamente la sentencia cita el caso de la portada "Las explosiones nerviosas del Presidente" (06/04/2016), como ejemplo de titulares "con connotación tendenciosa, quizás machista", excediendo la mera función informativa y crítica.

\section{Consideraciones finales}

En el presente trabajo hemos puesto el foco de nuestro estudio en los discursos sobre Dilma Rousseff por parte de algunos grandes medios de comunicación brasileños, durante el proceso de impeachment. Nuestro objetivo inicial estaba encaminado a averiguar cómo nos ayuda el tono, la entonación expresiva, la valoración, a observar la construcción de la intolerancia.

Volóchinov (2019, p. 287), siguiendo un proverbio popular, afirma que es el tono lo que hace la música para resaltar la importancia primordial de este en la producción de los sentidos. De esta manera, podemos decir que los tonos intolerantes producen significados intolerantes, constitutivos del discurso intolerante. La entonación, como explica el autor citado aqui arriba, es social por excelencia, sensible a los cambios que rodean al locutor, y está determinada por la situación y la audiencia. Por lo tanto, al observar los tonos intolerantes en los medios, percibimos, por un lado, la producción de una crítica intolerante destinada a Rousseff y, por otro lado, la presuposición de un coro de apoyo de personas con quienes se comparten valoraciones comunes, el cual no solo sustenta la producción del discurso intolerante, sino que también garantiza su recepción y circulación. Así, cuando no hay coro de apoyo, "la voz pierde fuerza, su riqueza entonativa se reduce"28 (/bid, p. 123-
124). Es decir, entendemos que, si los medios no tuvieran tal coro de apoyo, tal vez no producirian tales discursos, lo que nos permite afirmar que existe una retroalimentación de la intolerancia. Esta no solo legitima prácticas discriminatorias contra víctimas poco susceptibles en principio de convertirse en objeto de prejuicios, sino que también hace posible que una persona, al sentirse víctima de discriminación, considere el discurso como intolerante. En los análisis realizados, el hecho de que Rousseff es una mujer nos ha permitido interpretar los tonos intolerantes como machistas, vinculados a la discriminación de género, al destacar el "desequilibrio" y la "excitabilidad" como características femeninas incapacitantes para la vida profesional.

Esperamos, con el presente estudio, haber contribuido a reflexionar sobre la parte de responsabilidad de algunos de los principales medios de comunicación brasileños, impresos y en línea, en la construcción y propagación de discursos con tonos intolerantes, así como en la polarización de la sociedad al establecer una relación de odios y afectos, como observa Schwarcz (2019), naturalizando la falta de respeto a las diferencias (lugares ocupados, formas de vida, posiciones y convicciones), con el apoyo de una parte de la sociedad (ese coro de apoyo que hemos evocado anteriormente). Nuestras reflexiones, por otro lado, pretenden invitar a pensar sobre el importante papel de un medio responsable, que no solo debe promover la información, sino también la formación, respetando las diferencias, y convertirse en un agente activo, crítico, investigador y comprometido con los problemas sociales, capaz de reorientar su coro de apoyo hacia la defensa de valores democráticos.

Pensamos que, con la colaboración de medios activos a favor de la democracia, se podría enfrentar más eficientemente la actual crisis de intolerancia, restaurar la confianza en el futuro y reducir la frustración social, además auspiciar la defensa de la tolerancia, combatiendo los estereotipos y los discursos de plástico que pretenden

\footnotetext{
27 Las mayúsculas son de la sentencia judicial.

28 La traducción es nuestra.
} 
desinfectar la realidad (LÓPEZ-MUÑOZ, 2019)29. En este escenario, la divergencia de posiciones no sería objeto de intolerancia, sino que conduciría la sociedad al pluralismo agonista defendido por Mouffe (2010), que promueve la tolerancia a lo diferente sin considerarlo un enemigo, sino un oponente cuya existencia es legítima. La confrontación de posiciones es una condición para la existencia de una democracia pluralista, capaz de poner fin a las prácticas intolerantes.

\section{Bibliografía}

ALCÁCER GUIRAO, Rafael. Víctimas y disidentes. El 'discurso del odio' en EE. UU. y Europa. Revista Española de Derecho Constitucional, n. 103, p. 45-86, 2015.

ALCÁCER GUIRAO, Rafael. Libertad de expresión, negación del Holocausto y defensa de la democracia. Incongruencias valorativas en la jurisprudencia del TEDH. Revista Española de Derechos Constitucional, n. 97, p. 309-341, 2013

AMOSSY, Ruth. La présentation de soi - ethos et identité verbale. Paris: PUF, 2015.

BAKHTIN, Mikhail. Teoria do romance l: A estilistica. Organização da edição russa de Serguei Botcharov e Vadim Kójinov. Tradução, prefácio, notas e glossário de Paulo Bezerra. São Paulo: Editora 34, 2015.

BAKHTINE, Mikhail. Pour une philosophie de l'acte. Trad. Ghislaine C. Bardet. Paris: Editions L'Age d'Homme, 2003.

BARROS, Diana. Intolerância, preconceito e exclusão. In: LARA, G.P.; LIMBERTI, R.P. Discurso e (des)igualdade social. São Paulo: Contexto, 2015.

BERNIE, Jean-Paul. Formation de la citoyenneté et communautés discursives. Tréma, 15-16, 61-68, 1999 https://doi.org/10.4000/trema.1705

BERTONI, Eduardo A. Libertad de expresión en el Estado de derecho. Doctrina y jurisprudencia nacional, extranjera e internacional. Buenos Aires: Editores del Puerto, p. 179, 2007. Disponible en: https://bit. ly/3auGrIT.

CHARAUDEAU, Patrick. De l'état victimaire au discours de victimisation: Cartographie d'un territoire discursif. Argumentation et Analyse du Discours, n. 23 . p. 1-18, 2019. Disponible en: https://journals.openedition.org/aad/3408. https://doi.org/10.4000/aad.3408
CHARAUDEAU, Patrick. A conquista da opinião pública: como o discurso manipula as escolhas políticas. Trad. Angela M. S. Corrêa. São Paulo: Contexto, 2016.

DI FANTI, Maria da Glória Corrêa. Ethos e ato ético: o discurso intolerante e a politica brasileira em redes (sociais) de sentidos. Relatório de pesquisa (Pós-Doutorado no Exterior (PDE) - CNPq), 2019.

DI FANTI, Maria da Glória Corrêa; THEOBALD, Pedro; MELLO, Ana Maria Lisboa. Discurso, Memória, Alteridade: diálogos e confrontos identitários contemporâneos. Letrônica, v. 11, p. s1-s11, 2018. https://doi. org/10.15448/1984-4301.2018.S.31761

DROIT, Roger-Pol. Tolerância. Trad. Patricia Reuillard. São Paulo: Contexto, 2017.

DROIT, Roger-Pol. La tolérance expliquée à tous. Paris: Seuil, 2016.

DURAND, Gilbert. Les structures anthropologiques de l'imaginaire. Paris: Bordas, 1969.

ESPINOZA ARIZA, Jelmut. El derecho a la libertad de expresión contra el derecho a la libertad religiosa ¿Existe un derecho a blasfemar? A propósito de la revista Charlie Hebdo. Lex: Revista de la Facultad de Derecho y Ciencias Politicas de la Universidad Alas Peruanas, n. 15, p. 85-110, 2015. Disponible en: https:// dialnet.unirioja.es/servlet/articulo? codigo=5157761.

ESQUIVEL ALONSO, Yéssica 2016 El discurso del odio en la jurisprudencia del tribunal europeo de derechos humanos. Cuestiones Constitucionales. Revista Mexicana de Derecho Constitucional, v. 35, p. 3-44.

FERÉ, Liz. O poder das palavras: relações de alteridade no seio do povo brasileiro, entre branquitude e negritude. Letrônica, v. 11, p. S83-s99, 2018. https:// doi.org/10.15448/1984-4301.2018.5.30903

FERREIRO GALGUERA, Juan. Las caricaturas sobre Mahoma y la jurisprudencia del Tribunal Europeo de Derechos Humanos. Revista Electrónica de Estudios Internacionales, n. 12, p. 1-40, 2006. Disponible en: http://www.reei.org/index.php/revista/num12/articulos/caricaturas-sobre-mahoma-jurisprudencia-tribunal-europeo-derechos-humanos.

FUCHS, Catherine. L'incertitude interprétative dans l'activité de langage. Actes de savoirs, n. 5, p. 41-57, 2008

GAZALÉ, Olivia. Le mythe de la virilité. Paris: Éditions Robert Laffont, 2019.

GOFFMAN, Erving. On face-work: an analysis of ritual elements in social interaction. Psychiatry: Journal for the Study of Interpersonal Processes, n. 18, p. 213-231, 1955. https://doi.org/10.1080/00332747.1955.11023008

29 Nos referimos a una determinada práctica discursiva caracterizada por un conjunto de usos en los que predominan los textos braquilógicos, los actos principalmente locutorios, el borrado enunciativo y un léxico de palabras semánticamente subdeterminadas Resumidamente, se trata de discursos que, como el plástico, resultan fáciles de manejar, agradables, familiares, conocidos, rutinarios, sin aparentes efectos sobre el destinatario ni derivaciones negativas, al menos inmediatas. Con tales características, se puede hablar "en plástico" prácticamente de cualquier tema, con la certeza de que el mensaje va a ser bien recibido, sin requerir del interlocutor ninguna reacción más allá de la simple recepción de una información poco procesada o la adhesión a una idea con la que no se puede sino concordar. Los discursos de plástico se construyen, como detallamos en el artículo citado (LOPEZ-MUÑOZ, 2019, p. 67-68), sobre enunciados muy poco sensibles al contexto, de ahi que un mismo enunciado de plástico pueda ser susceptible de numerosas re-textualizaciones y circular ampliamente por la red. 
LAVERGNE, Lucie. Quand dire, c'est défaire. La parole aux vulnérables pour dénoncer et renverser la vulnérabilité, dans l'œuvre poétique de Maria Castrejón (1974). Discours et Société, n. 20, 2019. Disponible en: http://revue-signes.gsu.edu.tr/article/-LrY-29mXSRMRKTN3jiru.

LEVINSON, Stephen C. Presumptive Meanings. The Theory of Generalized Conversational Implicature. Cambridge: MIT Press, 2000.

LÓPEZ-MUÑOZ, Juan-Manuel. Discursos de plástico y desinformación en la comunicación digital. In: VENTURINI, Maria Cleci; LOREGIAN-PENKAL, Loremi; WITZEL, Denise Gabriel (org.). Linguistica na contemporaneidade: interfaces, memórias e desafios Campinas: Pontes Editores, p. 67-86, 2019.

LÓPEZ-MUÑOZ, Juan Manuel; DI FANTI, Maria da Glória Corrêa. Discursos (in)tolerantes y democracia pluralista. Letrônica, v. 13, n. 2, 2020.

LÓPEZ-MUÑOZ, Juan Manuel; CAPPONI, Paola. Los discursos intimidatorios: ¿de dónde vienen y adónde van? Fragmentum, n. 50, p. 9-17, 2017. https://doi. org/10.5902/2179219431701

MAILLARD, Chantal. ¿Es posible un mundo sin violencia? Madrid: Vaso Roto, 2018.

MAINGUENEAU, Dominique. Retorno crítico à noção de ethos. Tradução de Maria da Glória Corrêa di Fanti e Liz Feré. Letras de Hoje - Ethos discursivo: alcance, desafios e potencialidades, v. 53, p. 321-330, 2018 https://doi.org/10.15448/1984-7726.2018.3.32914

MEDVIÉDEV, P. (Círculo de Bakhtin). O método formal nos estudos literários: introdução crítica a uma poética sociológica. Trad. Sheila Camargo Grillo e Ekaterina Vólkova Américo. São Paulo: Contexto, 2012.

MOUFFE, Chantal. Politique et agonisme. Rue Descartes, v. 67, n. 1, p. 18-24, 2010. Disponible en: https://www.cairn.info/revue-rue-descartes-2010-1-page-18.htm.

RECANATI, François. Déstabiliser le sens. Revue internationale de philosophie, n. 216, v. 2, p. 197-208, 2001.

REVENGA SÁNCHEZ, Miguel (dir.). Libertad de expresión y discurso del odio. Madrid: Universidad de Alcalá, 2015. Disponible en: https://dialnet.unirioja. es/servlet/libro? codigo $=573313$.

REVENGA SÁNCHEZ, Miguel. La libertad de expresión y sus limites. Estudios, Loma: Ed. Jurídica Grijley, 2008.

REVENGA SÁNCHEZ, Miguel. Trazando los límites de lo tolerable: libertad de expresión y defensa del ethos democrático en la jurisprudencia española. Cuadernos de Derecho Público, n. 27, p. 23-43, 2004. Disponible en: https://dialnet.unirioja.es/servlet/ articulo? codigo $=1290786$.

REYES, Graciela. Palabras en contexto. Pragmática y otras teorias del significado. Madrid: Arco Libros, 2018.

RODRIGUEZ MONTAÑÉS, Teresa. Libertad de expresión, discurso extremo y delito. Una aproximación desde la Constitución a las fronteras del derecho penal. Valencia: Tirant lo Blanch, 2012.
SCHWARCZ, Lilia Moritz. Sobre o autoritarismo brasileiro. São Paulo: Companhia das Letras, 2019.

SURIN, Guillaume. De la vulnérabilité comme disposition. Jacques Derrida: Blessure, Ecriture, Pouvoir. Discours et Société, v. 20, 2019. Disponible en: http://revue-signes.gsu.edu.tr/article/-LrY-ggioaALGmAmAV_Y.

VOLÓCHINOV, Valentin. A palavra na vida e a palavra na poesia: ensaios, artigos, resenhas e poemas. Organização, tradução, ensaio introdutório e notas de Sheila Grillo e Ekaterina Vólkova Américo. São Paulo: Editora 34, 2019.

VOLÓCHINOV, Valentin. Marxismo e filosofia da linguagem: problemas fundamentais do método sociológico na ciência da linguagem. Trad., notas e glossário de Sheila Grillo e Ekaterina Vólkova Américo. São Paulo: Editora 34, 2017.

\section{Maria da Glória Corrêa di Fanti}

Doctora en Lingüística Aplicada y Estudios del Lenguaje en la Pontificia Universidad Católica de São Paulo (PUCSP) y profesora-investigadora en el Programa de Posgrado en Letras de la Facultad de Humanidades de la Pontificia Universidad Católica de Rio Grande do Sul (PUCRS). Becaria de Productividad de Investigación del CNPq.

\section{Juan Manuel López-Muñoz}

Doctor en Filologia Francesa pela Universidad de Cádiz y profesor titular del Departamento de Filología Francesa e Inglesa de la Facultad de Filosofía y Letras de la Universidad de Cádiz.

\section{Dirección:}

Maria da Glória Corrêa di Fanti

Pontificia Universidade Católica do Rio Grande do Sul (PUCRS)

Av. Ipiranga, 6681

Partenon 90619-900

Porto Alegre, RS, Brasil

Juan Manuel López-Muñoz

Universidad de Cádiz (UCA)

Av. Dr. Gómez Ulla, 1,

11003

Cádiz, Espanha 